\title{
Cumulative lactate and hospital mortality in ICU patients
}

\author{
Paul A van Beest ${ }^{1 *}$, Lukas Brander ${ }^{4}$, Sebastiaan PA Jansen ${ }^{3}$, Johannes H Rommes ${ }^{3}$, Michaël A Kuiper ${ }^{2,5}$ \\ and Peter E Spronk ${ }^{3,5}$
}

\begin{abstract}
Background: Both hyperlactatemia and persistence of hyperlactatemia have been associated with bad outcome. We compared lactate and lactate-derived variables in outcome prediction.

Methods: Retrospective observational study. Case records from 2,251 consecutive intensive care unit (ICU) patients admitted between 2001 and 2007 were analyzed. Baseline characteristics, all lactate measurements, and in-hospital mortality were recorded. The time integral of arterial blood lactate levels above the upper normal threshold of 2.2 $\mathrm{mmol} / \mathrm{L}$ (lactate-time-integral), maximum lactate (max-lactate), and time-to-first-normalization were calculated. Survivors and nonsurvivors were compared and receiver operating characteristic (ROC) analysis were applied.

Results: A total of 20,755 lactate measurements were analyzed. Data are srpehown as median [interquartile range]. In nonsurvivors $(\mathrm{n}=405)$ lactate-time-integral $(192[0-1881] \mathrm{min} \cdot \mathrm{mmol} / \mathrm{L})$ and time-to-first normalization (44.0 [0-427] $\mathrm{min}$ ) were higher than in hospital survivors ( $\mathrm{n}=1846 ; 0$ [0-134] $\mathrm{min} \cdot \mathrm{mmol} / \mathrm{L}$ and 0 [0-75] min, respectively; all $p<0.001$ ). Normalization of lactate $<6$ hours after ICU admission revealed better survival compared with normalization of lactate $>6$ hours (mortality $16.6 \%$ vs. $24.4 \% ; p<0.001$ ). AUC of ROC curves to predict in-hospital mortality was the largest for max-lactate, whereas it was not different among all other lactate derived variables (all $p>0.05$ ). The area under the ROC curves for admission lactate and lactate-time-integral was not different $(p=0.36)$.
\end{abstract}

Conclusions: Hyperlactatemia is associated with in-hospital mortality in a heterogeneous ICU population. In our patients, lactate peak values predicted in-hospital mortality equally well as lactate-time-integral of arterial blood lactate levels above the upper normal threshold.

Keywords: Lactate, Critically ill, Intensive care units, In-hospital mortality

\section{Background}

Hyperlactatemia is common in critically ill patients and may reflect an imbalance between local or systemic oxygen supply $\left(\mathrm{DO}_{2}\right)$ and oxygen consumption $\left(\mathrm{VO}_{2}\right)$. Hyperlactatemia also may be found during increased aerobic glycolysis in hypermetabolic states from various causes $[1,2]$, in patients treated with catecholamines $[3,4]$, as a consequence of alkalosis in hyperventilation [5], and with impaired hepatic lactate clearance in sepsis or low flow states [6]. Elevated lactate levels are associated with the development of multiple organ dysfunction (MODS) postoperatively, following trauma, and

\footnotetext{
*Correspondence: p.van.beest@umcg.nl

'Department of Anaesthesiology, University Medical Center Groningen,

University of Groningen, PO Box 30001, Groningen 9700 RB, the Netherlands Full list of author information is available at the end of the article
}

septic shock [7-10], and it has been suggested that hyperlactatemia is associated with worse outcome [10-13]. Persistence of lactate levels above normal is associated with higher mortality rates in patients with severe sepsis, septic shock $[9,14]$, and in postcardiac arrest patients [15].

We hypothesized that the severity of persistent hyperlactatemia represented by the time integral of arterial blood lactate levels above the upper normal threshold of $2.2 \mathrm{mmol} / \mathrm{L}$ (lactate-time-integral) outperforms single lactate measurements in predicting outcome. We therefore retrospectively investigated the relationship between lactate derived variables (admission level, maximum level, time-to-first-normalization, lactate-time-integral) and inhospital mortality in a large, mixed intensive care unit (ICU) population. Subgroup analysis was performed on

\section{实}


categories in which lactate has been described as predictor of mortality (sepsis and circulatory failure) [10-13]. Additionally, we looked at possible differences between survivors and nonsurvivors in the 24 hours after admittance [16].

\section{Methods \\ Setting}

A retrospective, observational study in a universityaffiliated teaching hospital where the ICU is a mixed, ten-bed, "closed format" department. There were no changes in medical staff during the study period. Case records from all ICU patients with available lactate measurements admitted during a 5-year period, January 2002 to December 2006, were identified in the ICU database. The study was approved by the Local Ethics Committee, which waived the need for informed consent.

\section{Data collection}

Data from all days spent in the ICU were collected retrospectively from the electronic patient data monitoring system and the hospital administration database. We collected demographic information, diagnosis, acute physiology and chronic health evaluation (APACHE II), all lactate levels, and relevant variables for calculation of daily assessed SOFA score (Table 1). Diagnosis classifications were based on the APACHE II classifications, hence diagnosis category weight [17]. Finally, length of stay in the ICU ( $\left.\operatorname{LOS}_{\mathrm{ICU}}\right)$, days in the hospital before discharge $\left(\mathrm{LOS}_{\mathrm{HOSP}}\right)$, and hospital survival were recorded.

\section{Lactate levels and derived variables}

Lactate levels were measured in arterial blood using point-of-care blood gas analyzers (Rapidlab 865, Siemens, Munich, Germany; upper normal limit $2.2 \mathrm{mmol} / \mathrm{L}$ ). The time integral for lactate levels above the upper normal threshold of $2.2 \mathrm{mmol} / \mathrm{L}$ was calculated during the entire ICU stay (lactate-time-integral) using custom-made software. We used a formula that, for practical reasons, assumed a linear change over time between measurements. Figure 1 illustrates four possible scenarios used for calculating lactate-time-integral.

Lactate buffer solutions for renal replacement therapy (RRT) and continuous epinephrine infusion were not used during the study period following the general policy in the unit.

\section{Statistical analysis}

The statistical package for the social sciences (SPSS 16.0.1 for Windows, Chicago, IL) was used for statistical analyses and additional software was used for graphics (Prism 5.0 for windows, La Jolla, CA) and comparison of ROC curves (MedCalc 11.2.1, Mariakerke, Belgium). Data are presented as mean $\pm \mathrm{SD}$ or median [interquartile
Table 1 Baseline and clinical characteristics

\begin{tabular}{|c|c|c|c|c|}
\hline Characteristic & $\begin{array}{l}\text { All } \\
n=2,251\end{array}$ & $\begin{array}{l}\text { Survivors } \\
n=1846\end{array}$ & $\begin{array}{l}\text { Nonsurvivors } \\
n=405\end{array}$ & $\begin{array}{l}p \\
\text { value }^{a}\end{array}$ \\
\hline Age (yr) & 66 (12-98) & $69(57-76)$ & $75(67-81)$ & \\
\hline Sex M : F (\%) & $61: 39$ & $61: 39$ & $60: 40$ & \\
\hline SAPS-II & $38(20-113)$ & $33(24-43)$ & $51(41-65)$ & $<0.001^{*}$ \\
\hline \multicolumn{5}{|l|}{ SOFA } \\
\hline APACHE ॥ & $17(10-54)$ & $15(11-19)$ & $23(17-28)$ & $<0.001^{*}$ \\
\hline $\begin{array}{l}\text { Admission } \\
\text { source (\%) }\end{array}$ & & & & $<0.01^{\#^{*}}$ \\
\hline Emergency & 20.2 & 20.4 & 19.3 & \\
\hline Surgical / OR & 43.7 & 47.3 & 27.0 & \\
\hline Medical & 27.2 & 23.7 & 43.1 & \\
\hline $\mathrm{CCU}$ & 8.0 & 7.5 & 10.1 & \\
\hline Other & 0.9 & 1.1 & 0.5 & \\
\hline Diagnosis (\%) & & & & $<0.01^{\#^{*}}$ \\
\hline Vascular surgery & 16.0 & 17.2 & 10.4 & \\
\hline $\begin{array}{l}\text { Abdominal } \\
\text { surgery }\end{array}$ & 22.4 & 23.5 & 17.2 & \\
\hline Other surgery & 9.8 & 10.9 & 4.9 & \\
\hline Heart failure & 14.8 & 12.3 & 26.4 & \\
\hline $\begin{array}{l}\text { Respiratory } \\
\text { failure }\end{array}$ & 11.8 & 11.5 & 13.4 & \\
\hline Gl bleeding & 3.8 & 4.3 & 1.5 & \\
\hline Neurological & 4.5 & 4.6 & 2.7 & \\
\hline Other & 3.7 & 3.9 & 4.2 & \\
\hline Sepsis & 13.1 & 11.8 & 19.2 & \\
\hline $\begin{array}{l}\text { Vasoactive } \\
\text { agent (\%) }\end{array}$ & 33 & 28 & 57 & $<0.001^{*}$ \\
\hline LOS ICU (days) & $2(1-5)$ & $2(1-5)$ & $3(1-8)$ & $<0.001^{*}$ \\
\hline LOS HOSP (days) & $14(7-27)$ & 15 (9-28) & $6(2-16)$ & $<0.001^{*}$ \\
\hline $\begin{array}{l}\text { In-hospital } \\
\text { mortality (\%) }\end{array}$ & 18 & & & \\
\hline
\end{tabular}

Data are presented as numbers and median (interquartile range). AUC, area under the curve; SAPS-II, simplified acute physiology score; APACHE II, acute physiology, age and chronic health evaluation; OR, operating room; CCU, cardiac care unit; Gl, gastrointestinal; vasoactive agent: noradrenaline, dopamine, dobutamine, phosphodiesterase inhibitor; LOS ICU, length of stay at intensive care; LOS HOSP, length of stay at hospital; ${ }^{a}$ Survivors vs. nonsurvivors; ${ }^{\mathrm{b}} \mathrm{All}$ normal lactate $(A \cup C=0)$ vs. all elevated lactate $(A \cup C>0)$; ${ }^{*}$ Statistically significant difference. Statistics by Chi-square tests" and Wilcoxon rank-sum tests.

range] as indicated by assessment of normal distribution (D'Agostino-Pearson omnibus normality test). Mann-Whitney $U$ test was used for not normally distributed data. Differences of admission source or admission diagnosis between groups of survivors and nonsurvivors and those with and without hyperlactatemia were assessed using the Chi-square test. Receiver operating characteristic (ROC) curves were used for the assessment of sensitivity and specificity of lactate-derived variables to predict in-hospital mortality. Areas under the ROC curves $\left(\mathrm{AUC}_{\mathrm{ROC}}\right)$ were compared by the method 


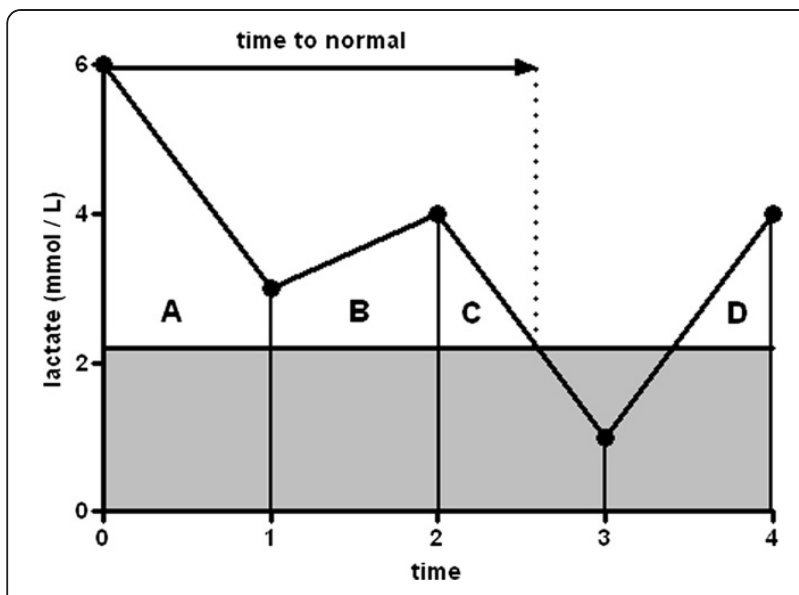

Figure 1 Calculation of lactate area under the curve above the upper normal limit of lactate $(2.2 \mathrm{mmol} / \mathrm{L})$. The following four equations were used in computing lactate-AUC: 1) AUC $A=((1 / 2$ $($ lactate 0 - lactate 1)) + lactate 1)) $\cdot($ time 1 - time 0); 2) AUC $\mathrm{B}=\left(\left(\frac{1}{2} \cdot(\right.\right.$ lactate $2-$ lactate 1$\left.)\right)+$ lactate 1$\left.)\right) \cdot($ time 2 - time 1$\left.) ; 3\right)$ AUC C $=\left((\text { lactate } 2-2.2)^{2} \cdot(\right.$ time 3 - time 2$\left.)\right) / 2 \cdot$ lactate $\left.2 ; 4\right)$ AUC $\mathrm{D}=\left((\text { lactate } 4-2.2)^{2} \cdot(\right.$ time $4-$ time 3$\left.)\right) / 2 \cdot$ lactate 4.

described by DeLong et al. [18]. Statistical significance was assumed at $p<0.05$.

\section{Results}

During the 5-year period, case records of 2,251 patients (age 66 [12-98] years; 39\% female) were identified. From all patients, at least one lactate sample was drawn and therefore none of the patients was excluded. A total of 20,755 lactate measurements were analyzed. Median lactate samples per day per patient was 2.0 [1.0-5.0] samples. Median lactate concentration at admission was 1.7 [1.1-2.8] $\mathrm{mmol} / \mathrm{L}$; minimum $0.6 \mathrm{mmol} / \mathrm{L}$ and $\max -$ imum $27.0 \mathrm{mmol} / \mathrm{L}$. Median max-lactate was 2.1 [1.5-3.3] $\mathrm{mmol} / \mathrm{L}$, and median lactate-time-integral 0.0 [0.0-244] $\mathrm{min} \cdot \mathrm{mmol} / \mathrm{L}$. Baseline and clinical characteristics of all patients are summarized in Table 1.

In-hospital mortality of our population was $18 \%$ and was higher in patients with hyperlactatemia during ICU stay compared with those without hyperlactatemia (26.4\% vs. $10.8 \%$; $p<0.001)$. Survival was significantly higher in patients with lactate normalization within 6 hours after ICU admission $(\mathrm{n}=1,856)$ compared with patients with lactate normalization $>6$ hours after ICU admission ( $\mathrm{n}=395 ; 16.6 \%$ vs. $24.4 \%$; $p<0.001$ ). For patients who died in the hospital $(n=405)$, admission lactate $(2.6$ [1.5-5.0] mmol/L), max-lactate (3.2 [1.9-5.8] $\mathrm{mmol} / \mathrm{L})$ time-to-first-normalization (44.0 [0-427] $\mathrm{min})$, and lactate-time-integral (192 [0-1,881] $\mathrm{min} \cdot \mathrm{mmol} / \mathrm{L})$, were higher than in-hospital survivors ( $n=1,846$; admission lactate $(1.6[1.1-2.5] \mathrm{mmol} / \mathrm{L})$, max-lactate (2.0 [1.4-3.0] $\mathrm{mmol} / \mathrm{L})$, time-to-first-normalization $(0.0[0-75] \mathrm{min})$ and lactate-time-integral 0 [0-134]
min.mmol/L, respectively; all $p<0.001$; Figure 2). Subanalysis for the first 24 hours showed similar results; all $p<0.001$.

Figure 3 demonstrates the difference between admission lactate levels and lactate-derived variables with respect to predicting in-hospital mortality. $\mathrm{AUC}_{\mathrm{ROC}}$ for admission lactate and lactate-time-integral were similar (0.666 [95\% confidence interval (CI) $0.646-0.686]$ vs. 0.676 [95\% CI $0.657-0.696] ; p=0.36)$. AUC $_{\mathrm{ROC}}$ for max-lactate $(0.692$ [95\% CI 0.672-0.711]) was larger than $\mathrm{AUC}_{\mathrm{ROC}}$ for admission lactate (0.666 [95\% CI 0.646-0.686]; $p=0.01)$ lactatetime-integral (0.676 [95\% CI 0.657-0.696]; $p<0.01)$, and

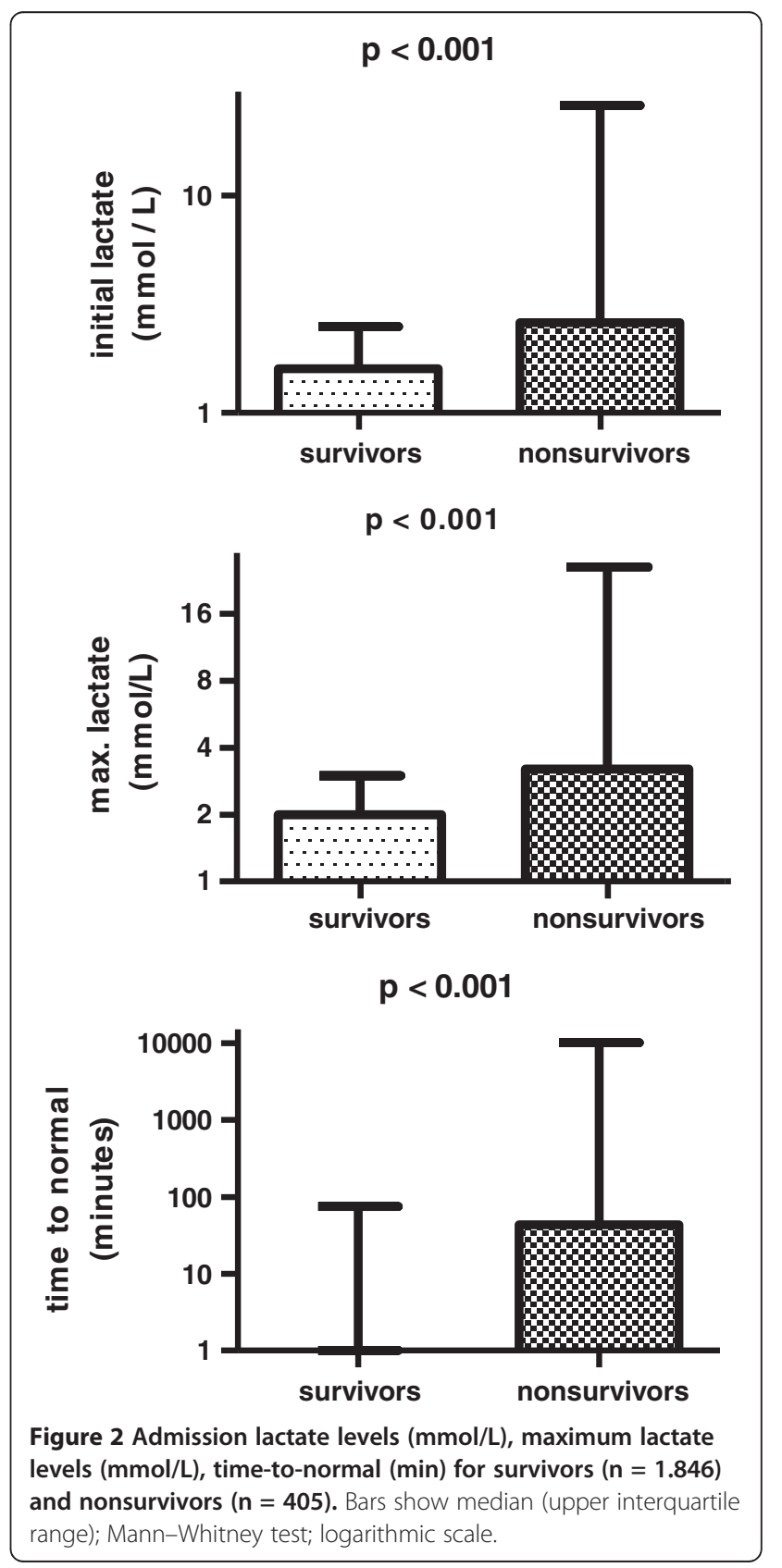




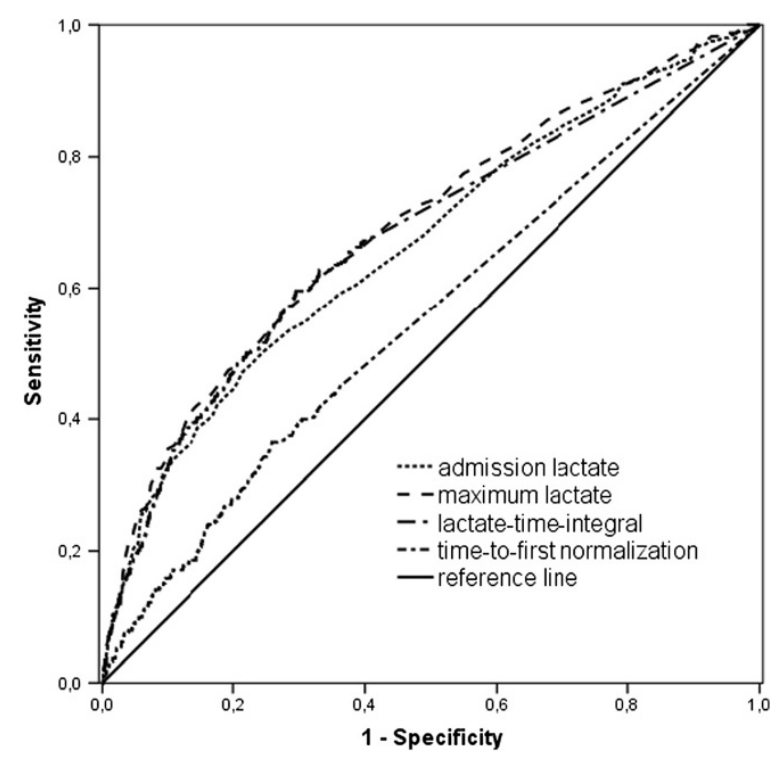

Figure 3 Receiver operating characteristic curves for in-hospital mortality prediction. Area under the curve was 0.552 for time-to -first-normalization, 0.666 for admission lactate, 0.676 for lactate-time -integral and 0.692 maximum lactate.

time to normal (0.552 [95\% CI 0.531-0.573]; $p<0.001)$. ROC curves for all four variables were significantly different from the reference line (all $p<0.01$ ). The cutoff points derived from the ROC curve for admission lactate, max-lactate and cumulative lactate were $2.7 \mathrm{mmol} / \mathrm{L}$, $2.5 \mathrm{mmol} / \mathrm{L}$, and $53 \mathrm{~min} \cdot \mathrm{mmol} / \mathrm{L}$, respectively. $\mathrm{AUC}_{\mathrm{ROC}}$ lactate-time-integral per day was $(0.672$ [95\% CI 0.641 0.694]; figure not shown).

$\mathrm{AUC}_{\mathrm{ROC}}$ for both time to normal and lactate-timeintegral were also calculated with other thresholds (thresholds $1.0 \mathrm{mmol} / \mathrm{L}, 2.0 \mathrm{mmol} / \mathrm{L}, 3.0 \mathrm{mmol} / \mathrm{L}$, and $4.0 \mathrm{mmol} / \mathrm{L}$ respectively). Table 2 summarizes the results for both total population and subgroups. None of these $\mathrm{AUC}_{\mathrm{ROC}}$ were significantly different from the reference line (all $p>0.05$ ).

In none of the subgroups (sepsis, $\mathrm{n}=307$; cardiac failure, $\mathrm{n}=213$; Table 3) $\mathrm{AUC}_{\mathrm{ROC}}$ for lactate-time-integral was larger than $\mathrm{AUC}_{\mathrm{ROC}}$ for single lactate values. In both subgroups admission lactate, maximum lactate and lactate-time-integral differed between survivors and nonsurvivors (all $p<0.001$ ). Analysis for the first 24 hours after admission showed similar results; in both subgroups all $p<0.01$.

\section{Discussion}

In the present study, lactate-time-integral was not superior in predicting in-hospital mortality compared with admission or maximum arterial lactate concentrations. Elevated admission lactate values, maximum lactate values during ICU stay, time-to-first-normalization, and
Table 2 AUC ROC curves with various thresholds

\begin{tabular}{lll}
\hline Threshold $^{\mathbf{a}}$ & Lactate-time-integral & Time-to-first-normalization \\
\hline Population & & \\
1 & & 0.514 \\
2 & 0.504 & 0.514 \\
3 & 0.504 & 0.518 \\
4 & 0.513 & 0.507 \\
Sepsis & 0.504 & \\
1 & & 0.535 \\
2 & 0.555 & 0.535 \\
3 & 0.555 & 0.544 \\
4 & 0.539 & 0.512 \\
Cardiac failure & 0.507 & \\
1 & 0.524 & 0.509 \\
2 & 0.524 & 0.509 \\
3 & 0.486 & 0.493 \\
4 & 0.493 & 0.482 \\
\hline
\end{tabular}

AUC ROC, area under receiver operating characteristic curve; ${ }^{a}$ lactate threshold presented in $\mathrm{mmol} / \mathrm{L} ;{ }^{b}$ normalization to respective threshold.

lactate-time-integral were all associated with in-hospital mortality. Data on the first 24 hours after admittance revealed similar results: lactate derived variables were significantly higher in nonsurvivors compared with survivors. However, the "dynamic" lactate index, i.e., lactate-time-integral, did not outperform the "static" lactate variables, i.e., admission lactate and maximum lactate.

High lactate clearance within the first 6 hours has been shown to be associated with decreased 60-day mortality, even in the absence of arterial hypotension; survivors compared with nonsurvivors had a lactate clearance of 38 vs. $12 \%$, respectively [14]. The present results also show a survival benefit for patients with lactate normalization within 6 hours in a heterogeneous ICU population. Recently, in a randomized study, the use of lactate clearance was described as an efficacious alternative for $\mathrm{ScvO}_{2}$-guided (target $>70 \%$ ) resuscitation of patients in septic shock [19]. However, due to practical reasons, a treatment bias could not be excluded. Also, difference in protocol actions was small; despite a well-performed study, chance may have influenced the results. In the present study, we did not evaluate lactate clearance as described in septic patients by Nguyen et al. $[14]$, i.e., as a ratio of lactate values. Instead, we evaluated a combination of the lactate-derived variables as a surrogate for lactate clearance. However, in the subgroup septic patients the lactate-time-integral or time-to -first-normalization did not outperform max-lactate. Lactime, described as a duration of hyperlactatemia, also has been shown to be the best discriminator of survival when the patients who died in the first 24 hours were 
Table 3 Baseline and clinical characteristics subgroups

\begin{tabular}{|c|c|c|}
\hline Characteristic & Sepsis $(n=307)$ & Cardiac failure $(n=213$ ) \\
\hline Age (yr) & $69[60-77]$ & $72[63-78]$ \\
\hline Sex $M: F(\%)$ & $63: 37$ & $60: 40$ \\
\hline SAPS $\|$ & $48[37-57]$ & $48[37-63]$ \\
\hline APACHE $\|$ & $21[17-26]$ & $22[16-28]$ \\
\hline Heart rate (beats/min) & 115 [96-130] & $110[80-125]$ \\
\hline Systolic blood pressure $(\mathrm{mmHg})$ & $105[80-130]$ & $110[85-140]$ \\
\hline Mean arterial pressure (mmHg) & $58[50-62]$ & $59[51-65]$ \\
\hline Vasoactive agent (\%) & 56 & 56 \\
\hline Lactate (mmol/L) & $2.4[1.6-3.9]$ & $2.4[1.4-4.8]$ \\
\hline Maximum lactate (mmol/L) & $3.0[2.1-4.9]$ & $3.0[1.9-5.2]$ \\
\hline Cum-lactate (min·mmol/L) & $216[0-2634]$ & $138[0-1245]$ \\
\hline In-hospital mortality (\%) & 29 & 38 \\
\hline
\end{tabular}

Data are presented as numbers and median [interquartile range]. SAPS-II, simplified acute physiology score; APACHE II, acute physiology, age and chronic health evaluation.

excluded [10]. We performed a retrospective study and choose not to exclude those patients who died early after onset of the disease to picture the influence of lactate and lactate-derived variables in clinical reality. In conclusion, the present results recognize the importance of lactate clearance as described by others but also underline the importance of magnitude of lactate values during ICU treatment. In other words, time to first normalization may not be a key factor. This is clinically important: we need continuous reassessment of lactate levels to guide our resuscitation efforts.

A lactate threshold $\geq 4 \mathrm{mmol} / \mathrm{L}$ has been used to initiate protocol-based resuscitation [20,21]. Such an approach might imply acceptance of intermediate lactate levels in the range of 2 to $4 \mathrm{mmol} / \mathrm{L}$. However, elevated mortality rates also are described in critically ill patients with only moderately elevated lactate levels during or even before admission to the emergency department (ED) [22-24]. Additionally, in two recent retrospective studies the relationship between lactate levels, lactatederived variables, and outcome in critically ill patients was assessed. It was concluded that not only hyperlactatemia but also relative hyperlactatemia, i.e., lactate levels in the upper normal range, are associated with increased mortality [16,25]. Our results in ICU patients are concordant with these results, and we believe that normal values provide a reasonable clinical sign that tissue oxygenation is adequate and the metabolism is primarily aerobic. Of note, a higher lactate concentration threshold revealed different results: higher thresholds did not enhance predictive value for outcome. Indeed, not every hyperlactatemia is associated with acidosis, which is an important contributor to worse outcome. This might explain why lactate-time-integral does not outperform peak lactate values in outcome prediction in the present cohort. However, one could argue on the clinical relevance of the significant yet small difference in $\mathrm{AUC}_{\mathrm{ROC}}$ of peak lactate and $\mathrm{AUC}_{\mathrm{ROC}}$ of lactate-time-integral (0.692 vs. 0.676; $p<0.01)$. Definitive conclusions probably should not be made on such small differences. On the other hand, our results do not confirm superiority of dynamic lactate variables over static lactate variables as suggested earlier [16].

In addition, two other factors may be responsible for this finding. First, the retrospective design of our study and the lack of a specific intervention protocol limits the generalization of our results. Second, arterial lactate concentrations not only depend on lactate production but also on its clearance. It is not known whether one mechanism is more important than the other with respect to outcome prediction. Nevertheless, the mechanism causing hyperlactatemia may play an important role in outcome prediction, rather than the hyperlactatemia itself. For instance, as described in two recent reports $[26,27]$, the severity of hyperlactatemia due to metformin accumulation alone does not predict outcome but even in those cases the causative role is uncertain. Also, comorbidities, such as renal insufficiency of liver failure, may play an additional role [26,27].

Finally, patients who died early, i.e., within 24 hours, possibly could not accumulate enough lactate-time-integral values despite disease severity. Establishment of a relationship between the lactate-time-integral and survival therefore could be disturbed. However, when the length of ICU stay was taken into account, the $\mathrm{AUC}_{\mathrm{ROC}}$ was not larger and the lactate-time-integral per day did not perform better than peak lactate.

Nonsurvivors revealed shorter $\operatorname{LOS}_{\mathrm{ICU}}$ and $\mathrm{LOS}_{\mathrm{HOSB}}$ whereas lactate-time-integral was significantly higher in nonsurvivors compared with survivors. The duration 
and magnitude of increased lactate levels, represented by the area under the lactate curve, is associated with final outcome. Nevertheless, in the present study, the specificity and sensitivity, described by $\mathrm{AUC}_{\mathrm{ROC}}$, of admission lactate and lactate-time-integral were similar in predicting inhospital mortality. However, the present results on this large heterogeneous population underline the importance of ongoing watchfulness during the entire ICU stay.

Several limitations to our observations should be considered. First, this was a retrospective study, which precludes definitive conclusions. Also, there was no predefined lactate measurement or lactate-based goaldirected protocol. However, we consider the results strong enough to warrant further prospective studies analyzing the described phenomena, particularly because the data were collected over a 5-year period and derived from a large group of patients. Second, this was a singleunit study in one Dutch ICU, and therefore the results may only reflect the regional population and ICU management strategies. Nevertheless, we believe that selection bias was minimized, because all consecutive admissions were included in the data analysis and because there was no change in medical staffing, and admission and discharge criteria were stable during the study period. Third, we assumed a linear change in time between two lactate measurements, which is a simplification of a real biologic process. However, we believe that our approach represents an approximation with acceptable precision for the purpose of the present study.

\section{Conclusions}

We conclude that hyperlactatemia is associated with inhospital mortality in a heterogeneous ICU population. In our patients, lactate peak values predicted in-hospital mortality equally well as lactate-time-integral of arterial blood lactate levels above the upper normal threshold. In a heterogeneous ICU population, normalization of lactate within 6 hours is associated with lower mortality. Thus, concerning lactate levels in a heterogeneous ICU population magnitude matters and ongoing watchfulness on elevated lactate levels is warranted for time to first normalization may not be the key factor.

\section{Abbreviations}

APACHE: Acute physiology age and chronic health evaluation; $A \cup C_{R O C}$ : Area under the ROC curve; $\mathrm{DO}_{2}$ : Systemic oxygen supply; ED: Emergency department; ICU: Intensive care unit; LOS ICU: Length of ICU stay;

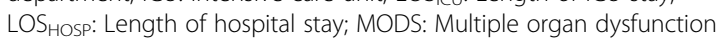
syndrome; ROC: Receiver operating characteristic; RRT: Renal replacement therapy; SOFA: Sequential organ failure assessment; $\mathrm{VO}_{2}$ : Systemic oxygen consumption.
}

\section{Competing interest}

The authors state that they have no conflicts of interest.

\section{Authors' contributions}

PB drafted the manuscript and performed statistical analysis. LB participated in the design of the study and helped to draft the manuscript. SJ designed custom-made software. JR participated in the design of the study and helped to draft the manuscript. MK helped to draft the manuscript and provided general support. PS conceived of the study and participated in its design and coordination and helped to draft the manuscript. All authors have read and approved the final manuscript.

\section{Author details}

'Department of Anaesthesiology, University Medical Center Groningen, University of Groningen, PO Box 30001, Groningen 9700 RB, the Netherlands. ${ }^{2}$ Department of Intensive Care Medicine, Medical Center Leeuwarden, PO Box 888, Leeuwarden 8901 BR, the Netherlands. ${ }^{3}$ Department of Intensive Care Medicine, Gelre Hospitals, location Lucas, PO Box 9014, Apeldoorn 7300 DS, the Netherlands. ${ }^{4}$ Department of Anesthesia and Intensive Care Medicine, Luzerner Kantonsspital, Luzern 6000, Switzerland. ${ }^{5}$ HERMES Critical Care Group, Amsterdam, The Netherlands.

Received: 24 September 2012 Accepted: 5 February 2013 Published: 27 February 2013

\section{References}

1. Gutierrez G, Wulf ME: Lactic acidosis in sepsis: a commentary. Intensive Care Med 1996, 22:6-16.

2. Mizock BA: Redox repairs, tissue hypoxia, organ dysfunction, and mortality. Crit Care Med 2000, 28:270-272.

3. Day NPJ, Phu NH, Bethell DP, Mai NTH, Chau TTH, White NJ: The effects of dopamine and adrenaline infusions on acid-base balance and systemic haemodynamics in severe infection. Lancet 1996, 348:219-223.

4. Levy B, Bollaert PE, Charpentier C, Nace L, Audibert G, Bauer P, Nabet P, Larcan A: Comparison of norepinephrine and dobutamine to epinephrine for hemodynamics, lactate metabolism, and gastric tonometric variables in septic shock: a prospective, randomized study. Intensive Care Med 1997, 23:282-287.

5. Druml W, Grimm G, Laggner AN, Lenz K, Schneeweiß B: Lactic acid kinetics in respiratory alkalosis. Crit Care Med 1991, 19:1120-1124.

6. Levraut J, Ciebiera J-P, Chave S, Rabary O, Jambou P, Carles M, Grimaud D: Mild hyperlactatemia in stable septic patients is due to impaired lactate clearance rather than overproduction. Am J Respir Crit Care Med 1998, 157:1021-1028.

7. Abramson D, Scalea TM, Hitchcock R, Trooskin SZ, Henry S, Greenspan J: Lactate clearance and survival following injury. J Trauma 1993, 35:584-589.

8. Donati A, Cornacchini O, Loggi S, Caporelli S, Conti G, Falcetta S, Alò F, Pagliariccio G, Bruni E, Presier JC, Pelaia P: A comparison among portal lactate, intramucosal sigmoid $\mathrm{Ph}$, and deltaCO2 ( $\mathrm{PaCO} 2$ - regional $\mathrm{PCO} 2$ ) as indices of complications in patients undergoing abdominal aortic aneurysm surgery. Anesth Analg 2004, 99:1024-1031.

9. Callaway DW, Shapiro NI, Donnino MW, Baker C, Rosen CL: Serum lactate and base deficit as predictors of mortality in normotensive elderly blunt trauma patients. J Trauma 2009, 66:1040-1044.

10. Bakker J, Gris P, Coffernils M, Kahn RJ, Vincent JL: Serial blood lactate levels can predict the development of multiple organ failure following septic shock. Am J Surg 1996, 171:221-226.

11. Tuchschmidt J, Fried J, Swinney R, Sharma OMP: Early hemodynamic correlates with survival in patients with septic shock. Crit Care Med 1989, 17:719-723.

12. Weil MH, Afifi AA: Experimental and clinical studies on lactate and pyruvate as indicators of the severity of acute circulatory failure (shock). Circulation 1970, 41:989-1001.

13. Bakker J, Coffernils M, Leon M, Gris P, Vincent JL: Blood lactate levels are superior to oxygen-derived variables in predicting outcome in human septic shock. Chest 1991, 99:956-962.

14. Nguyen HB, Rivers EP, Knoblich BP, Jacobsen G, Muzzin A, Ressler JA Tomlanovich MC: Early lactate clearance is associated with improved outcome in severe sepsis and septic shock. Crit Care Med 2004, 32:1637-1642.

15. Donnino MW, Miller J, Goyal N, Loomba M, Sankey SS, Dolcourt B, Sherwin R, Otero R, Wira C: Effective lactate clearance is associated with improved outcome in post-cardiac arrest patients. Resuscitation 2007, 75:229-234.

16. Nichol A, Baily M, Egi M, Pettila V, French C, Hart GK, Stachowski E, Reade MC, Cooper DJ, Bellomo R: Dynamic lactate indices as predictors of outcome in critically ill patients. Crit Care 2011, 15:R242. 
17. Knaus WA, Draper EA, Wagner DP, Zimmermann JE: APACHE II A severity of disease classification system. Crit Care Med 1985, 13:818-829.

18. DeLong ER, DeLong DM, Clarke-Pearse DL: Comparing the areas under two or more correlated receiver operating characteristic curves: a nonparametric approach. Biometric 1988, 44:837-845.

19. Jones AE, Shapiro NI, Trzeciak S, Arnold RC, Claremont HA, Kline JA, (EMShockNet) Investigators: Lactate clearance vs central venous oxygen saturation as goals of early sepsis therapy: a randomized clinical trial. JAMA 2010, 303:739-746.

20. Rivers E, Nguyen B, Havstad S, Ressler J, Muzzin A, Knoblich B, Peterson E, Tomlanovich M, for the Early Goal-Directed Therapy Collaborative Group: Early Goal-Directed Therapy in the treatment of severe sepsis and septic shock. N Engl J Med 2001, 345:1368-1377.

21. Dellinger RP, Carlet JM, Masur H, Gerlach H, Calandra T, Cohen J, Gea-Banacloche J, Keh D, Marshall J, Parker MM, Ramsay G, Zimmerman JL, Vincent JL, Levy MM, for Surviving Sepsis Campaign: Surviving Sepsis Campaign quidelines for management of severe sepsis and septic shock. Crit Care Med 2004, 32:858-873.

22. Howell MD, Donnino M, Clardy P, Talmor D, Shapiro NI: Occult hypoperfusion and mortality in patients with suspected infection. Intensive Care Med 2007, 33:1892-1899.

23. Mikkelsen ME, Miltiades AN, Gaieski DF, Goyal M, Fuchs BD, Shah CV, Bellamy SL, Christle JD: Serum lactate is associated with mortality in severe sepsis independent of organ failure and shock. Crit Care Med 2009, 37:1670-1677

24. van Beest PA, Mulder PJ, Bambang Oetomo S, Van den Broek B, Kuiper MA Spronk PE: Measurement of lactate in a prehospital setting is related to outcome. Eur J Emerg Med 2009, 16:318-322.

25. Nichol AD, Egi M, Pettila V, Bellomo R, French C, Hart G, Davies A, Stachowski E, Reade MC, Bailey M, Cooper DJ: Relative hyperlactatemia and hospital mortality in critically ill patients: a retrospective multicentre study. Crit Care 2010, 14:R25.

26. Friesecke $S$, Abel $P$, Roser M, Felix SB, Runge $S$ : Outcome of severe lactic acidosis associated with metformin accumulation. Crit Care 2010, 14:R226.

27. Protti A, Russo R, Tagliabue P, Vecchio S, Singer M, Rudiger A, Foti G, Ross A, Mistraletti G, Gattinoni L: Oxygen consumption is depressed in patients with lactic acidosis due to biguanide intoxication. Crit Care 2010, 14:R22.

doi:10.1186/2110-5820-3-6

Cite this article as: van Beest et al:: Cumulative lactate and hospital mortality in ICU patients. Annals of Intensive Care 2013 3:6.

\section{Submit your manuscript to a SpringerOpen ${ }^{\circ}$ journal and benefit from:}

- Convenient online submission

- Rigorous peer review

- Immediate publication on acceptance

- Open access: articles freely available online

- High visibility within the field

- Retaining the copyright to your article 